\title{
Modeling erosion and channel movement - response to rainfall variability in South East Australia
}

\author{
$\underline{\text { G.R. Hancock }}^{\text {a }}$ T.J. Coulthard ${ }^{b}$ and G. R. Willgoose ${ }^{c}$ \\ ${ }^{a}$ School of Environmental and Life Sciences, The University of Newcastle, Callaghan, \\ New South Wales, 2308, Australia \\ Email: Greg.Hancock@newcastle.edu.au \\ ${ }^{b}$ Department of Geography, University of Hull, Hull, HU6 7RX, UK \\ ${ }^{c}$ School of Engineering, The University of Newcastle, Callaghan, \\ New South Wales, 2308, Australia
}

\begin{abstract}
Catchments and channel networks continually adjust to fluctuations in stream discharge and sediment load as the fluvial system responds to both extrinsic and intrinsic forcings. External forcings may include climate and tectonics, whereas examples of internal forcings are land cover and land use changes as well as autogenic adjustments within the system itself (Nicholas and Quinne, 2007). While it is well recognised that erosion or channel aggradation is usually associated with increased amount or intensity of precipitation, subtle thresholds may operate where differences in rainfall events and resultant sediment delivery (increase or decrease in stream power) may produce rapid change in erosion rates and patterns. Therefore, apparently similar systems can respond differently under similar conditions (Knighton, 1998).
\end{abstract}

Hillslope erosion or channel aggradation is usually associated with increased amount or intensity of precipitation, yet subtle thresholds may operate where differences in rainfall events and resultant sediment delivery may produce rapid change in erosion rates and patterns. Here a modelling approach, using a landscape evolution model (CAESAR) is used to investigate hillslope erosion and sensitivity of channel position and movement under a series of realistic rainfall scenarios for a low-rainfall catchment $(\sim 600 \mathrm{~mm}$ per annum) with ephemeral streams in South-Eastern Australia.

Considerable research has already been undertaken to understand the intrinsic and extrinsic forces on catchment and stream channel change driven by a real need to predict how different systems respond under different forcings (Knighton, 1998). However, this is especially difficult to understand if the changes occur at different thresholds and relatively small changes in rainfall leads to significant change. To understand and quantify these responses is often difficult as periods of low and high rainfall and associated discharge may be symptomatic of particular regions ands climate regimes (Erskine and Warner, 1988; Verdon et al., 2004).

The fluvial system could be described in terms of inputs such as rainfall which is ultimately manifested in outputs such as an erosion response (Knighton, 1998). Pulsed inputs and ramped inputs can produce different sediment and morphological response. The pulsed input or high discharge events can route water and sediment outside the channel boundaries producing channel breakouts, new channels being cut, breakouts and avulsions and in large river systems the shortening and cut-off of meanders (Knighton, 1998). Whereas it is generally recognised that events of ramped change produce incremental erosion where the movement of soil is slow and gradual and are more likely the result of long-term climate shifts (Knighton, 1998; Erskine and Warner 1988 Nicholas and Quinne, 2007). While changes in a catchment may be predicated by the intensity and magnitude of the rainfall event (Solyom and Tucker, 2004), the catchment history (i.e. the surface topography and former channels that may reactivate) is also an important factor, as well as vegetation and human management practices.

The modelling results here demonstrate the sensitivity of the catchment to different rainfall patterns and how relatively small changes in rainfall can lead to much larger sediment outputs revealing sensitivity to subtle changes in climate. Channel movement occurs as an avulsion. This is the first time such a process has been observed and modeled in an ephemeral stream environment and demonstrates fluvial geomorphic change at human time scales. Overall the CAESAR landscape evolution and erosion model used in this study is able to replicate both erosion rates and the variation in past channel movement.

Keywords: soil erosion modelling, digital elevation model, climate change, climate variability, CAESAR 


\section{INTRODUCTION}

There are two ways catchment and channel change can be investigated. Firstly, using field data and secondly using a modelling approach. Field data is extremely valuable as individual catchments and stream systems can be examined. Historical evidence such as paleochannels, sediment records together with relative and absolute dating techniques allow landscape reconstruction and can be used to constrain process and form as well as rainfall and flood return intervals. Individual events can be studied resulting in a detailed qualitative as well as quantitative understanding. Direct observations and photographic records can also provide reliable data (Knighton, 1998). Nevertheless due to the difficulties in age constraints, reworking, and problems of back calculating antecedent conditions, interpretations of process and form may be more qualitative than quantitative. Therefore separating and understanding the various landscape sensitivities may prove difficult.

Modelling offers an alternative as various catchment controls can be held constant and a single model variable-changed. This allows a detailed analysis of both process and form to be performed. The difficulty with modelling is that a model is ultimately a simplified version of a natural system and can lack important functionality. Nevertheless, models can and have provided considerable insight into the subtleties and thresholds of geomorphic and hydrological systems particularly the influence of rainfall distribution and intensity on landscape evolution (Solyom and Tucker, 2004).

There are several soil erosion and landscape evolution models that use digital elevation models to represent the landscape surface that have been developed (see Coulthard, 2001; Tucker and Hancock, 2010 for model reviews). These models can also determine both erosion and deposition over a range of space and time scales including the channel network, something not possible with conventional modelling approaches. A further advantage of using digital elevation based models is that they dynamically adjust the hillslope and channel network in response to runoff, erosion and deposition, producing a better representation of slope and angle over the duration of the simulation. A recent advance is that these models now have the ability to employ spatially variable hydrology and erosion parameters, the spatial distribution of soil particle size at user defined soil depths as well as several different runoff and sediment flow direction algorithms. Some of these models can also employ temporally varying rainfall patterns allowing different rainfall-runoff scenarios to be examined.

This study applies CAESAR, a numerical landscape evolution and soil erosion model, to investigate the role of different rainfall regimes on sediment transport and resultant hillslope erosion and channel change in a small relatively low rainfall catchment with ephemeral streams. he results demonstrate the sensitivity of the catchment to different rainfall patterns and how relatively small changes in rainfall can lead to much larger sediment outputs revealing a sensitivity to subtle changes in climate.

\section{SITE DESCRIPTION}

This study is based within the 150 ha Stanley catchment in the Upper Hunter region of New South Wales, Australia. The Stanley catchment is a tributary of the $562 \mathrm{~km}^{2}$ Krui River catchment (Figures 1 and 2) (see Rudiger et al., 2007 for available site data and details). The Stanley catchment is currently a biodynamic (organic) beef cattle grazing property. The site is located in the temperate zone of eastern Australia. The average annual rainfall for the area is $624 \mathrm{~mm}$ with distribution evenly spread across all months (www. bom.gov.au). The Stanley catchment is underlain by Tertiary Basalt of the Liverpool Range beds and forms part of the Merriwa Plateau. Soils in the catchment consist of black dermosols on the ridge line, red dermosols on the hillslopes and vertosols on the creek flat. The catchment flora is dominated by native grasses with scattered eucalypt species and is classified as eucalypt tree savannah, with sparse tree cover. 


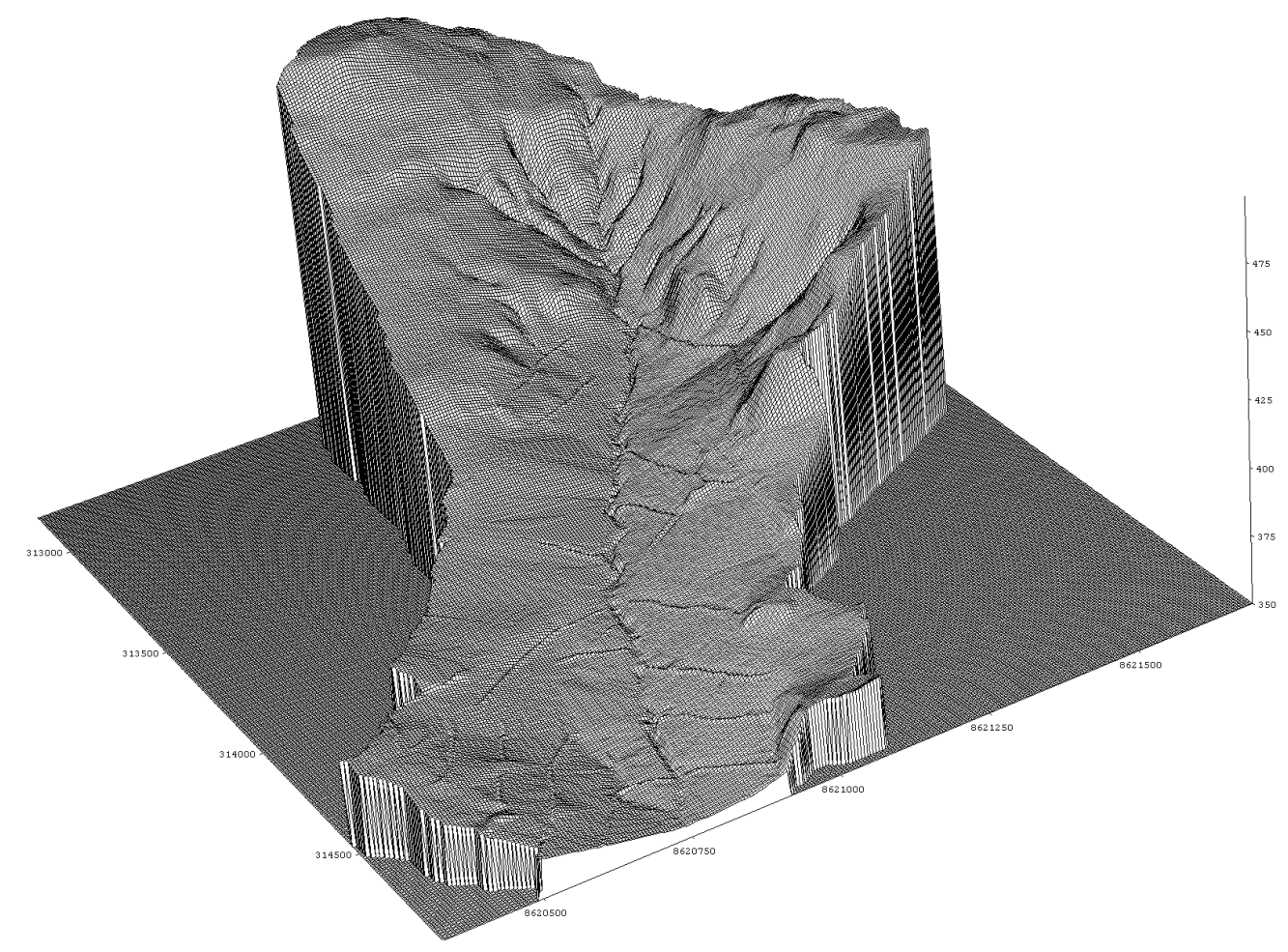

Figure 2 Digital elevation model ( $5 \mathrm{~m}$ by $5 \mathrm{~m}$ grid size) of the Stanley catchment. White dotted line indicates the former channel. Dimensions are all metres.

\section{THE CAESAR LANDSCAPE AND EROSION MODEL}

CAESAR is a numerical model that simulates the geomorphic evolution of landforms subjected to fluvial and diffusive erosion and mass transport processes. The model links accepted hydrology and erosion models under the action of runoff and erosion at hourly and longer time scales. It allows the user to input a digital elevation model (DEM) of a river catchment or reach, enter water and sediment fluxes, and/or rainfall data to drive catchment evolution. It features slope processes (soil creep, mass movement), hydrological processes, multidirectional routing of river flow and fluvial erosion and deposition over a range of different grainsizes. Bedrock depth can also be input as a DEM on the same dimensions as the surface DEM. A full description of CAESAR can be found in Van de Wiel et al. (2007).

CAESAR represents a landscape with a mesh of grid cells. For each cell, further values are stored representing hydrological parameters, grainsize, water discharge, vegetation levels etc. Then, for every model iteration, these are altered according to a set of rules, loosely grouped into (1) hydrology, (2) hydraulic routing, (3) fluvial erosion and deposition, and (4) slope processes. A modification of TOPMODEL (Beven and Kirkby, 1979) is used to generate a combined surface and subsurface discharge. For hydraulic routing the model takes a discharge either prescribed from a point, or determined with the built-in hydrological model and then routes this to neighbouring cells with boundary conditions and catchment outlet being determined by the user. This is carried out through a 'scanning' procedure that works across the catchment in four directions (left to right, right to left, up to down, down to up) pushing flow to the three cells in front. In CAESAR the flow depth is calculated for this discharge, which allows flow to be routed over, as well as around, obstacles.

After the hydraulic model has determined flow depths and inundation locations for the reach/catchment, fluvial erosion is calculated using 9 different grainsizes embedded within a series of active layers. This allows bed armouring effects and the development of a limited stratigraphy. Soil creep is calculated and mass movement (landslides) can occur when a critical slope threshold is exceeded based on slope alone and a diffusivity coefficient. 


\subsection{CAESAR input parameters}

CAESAR requires a digital elevation model (DEM) of the catchment of interest, rainfall $\left(\mathrm{mm} \mathrm{hr}^{-1}\right)$ and soil/sediment particle distribution data. It also has the ability to employ a DEM of the bedrock. These data sets are described below.

As $5 \mathrm{~m}$ grid resolution DEM of the Stanley catchment was created from measurements made using a Trimble 4700 base station and rover (Differential Global Positioning System - DGPS). The data was gridded using triangulation with smoothing (Vertical Mapper, v. 2.6) to produce a 5m DEM (Figure 2).

Pluviograph data from three nearby rainfall stations, Roscommon, Cassilis and Scone were used (www.bom.gov.au). Roscommon, located approximately $5 \mathrm{~km}$ from the site had an annual average rainfall of $525 \mathrm{~mm} / \mathrm{yr}$ (October 2000 to June 2007) this being below average for the area due to drought between 2003 and 2007. Nevertheless the data contained a major rainfall period in June 2007 which had a daily rainfall event of $117 \mathrm{~mm}$ and a maximum hourly rainfall of $48 \mathrm{~mm}$. This is the largest event since the station opened in 1969 and is potentially a 1:50 year event.

Cassilis located approximately $15 \mathrm{~km}$ from the site had average annual rainfall of $623 \mathrm{~mm} / \mathrm{yr}$ (March 1997 to January 2004) approximating the long-term annual rainfall average for the area. Only complete annual data was used. There is no pluviograph data available past January 2004. This data set contained no exceptionally high rainfall events to note with the maximum hourly rainfall event being $28 \mathrm{~mm}$.

The next closest site, Scone, was located approximately $60 \mathrm{~km}$ North-East from the study site and has an average annual rainfall of $646 \mathrm{~mm} / \mathrm{yr}$

(May 1999 to May 2007) approximating the long-term annual rainfall average for the area. Similar to the Cassilis data, the Scone pluviograph data contained no exceptionally high rainfall events to note with the maximum hourly rainfall event being $28 \mathrm{~mm}$. These three data sets, originally at six-minute intervals were regrouped to hourly time intervals for input into CAESAR and added end to end to produce a continuous 1000 year record

Table 1. Soil particle size used for the simulations.

\begin{tabular}{|c|c|c|c|c|c|c|c|}
\hline $\begin{array}{l}\text { Size } \\
(\mathrm{mm})\end{array}$ & $55 \%$ & $\begin{array}{l}\text { Size } \\
(\mathrm{mm})\end{array}$ & $56 \%$ & $\begin{array}{c}\text { Size } \\
(\mathrm{mm})\end{array}$ & $57 \%$ & $\begin{array}{l}\text { Armour } \\
\text { (mm) }\end{array}$ & $\begin{array}{l}\text { Size } \\
(\mathrm{mm})\end{array}$ \\
\hline 0.00015 & 0.77 & <0.00015 & 0.14 & <000015 & 0.24 & <.0.0015 & 0.04 \\
\hline 0.00025 & 0.01 & 000025 & 0.04 & 00005 & 0.02 & 000025 & 0.00 \\
\hline 00005 & 0.01 & 0004 & 0.04 & 0.001 & 0.01 & 00005 & 0.01 \\
\hline 0.001 & 0.01 & 0008 & 0.06 & 0.002 & 0.02 & 0.001 & 0.02 \\
\hline 0.002 & 0.01 & 0016 & 0.15 & 0.004 & 0.03 & 0.002 & 0.03 \\
\hline 0.004 & 0.01 & 0032 & 0.13 & 0.008 & 0.03 & 0.004 & 0.03 \\
\hline 0.008 & 0.01 & 005 & 0.18 & 0.016 & 0.04 & 0.008 & 0.10 \\
\hline 0.016 & 0.01 & 0.1 & 0.13 & 0.080 & 0.36 & 0.016 & 0.26 \\
\hline$>0050$ & 0.16 & $>0.15$ & 0.13 & $>0.15$ & 0.25 & $>0050$ & 0.49 \\
\hline
\end{tabular}

Soil particle size data were obtained from soil pits dug at three representative sites at the top, middle and bottom of the slope adjacent S5, S6 and S7 (Figure 1). These represented the major soil types in the catchment with the S5, S6 and S7 soils representing the area of the catchment between $350 \mathrm{~m}-400 \mathrm{~m}, 400 \mathrm{~m}-$ $450 \mathrm{~m}$ and above $450 \mathrm{~m}$ elevation, respectively. These data will be referred to as the S5, S6 and S7 parameter sets in all text below.(Table 1).

\section{RESULTS}

\subsection{Erosion rates}

Sediment output from the catchment had a unique episodic pattern in response to the different rainfall inputs. The Roscommon rainfall produced the highest peaks in sediment output in response to the storm event in June 2007 that repeats in the rainfall sequence. The unique episodic pattern varies throughout the simulation demonstrating that sediment output varies considerably (also expressed as a standard deviation from the mean, Table 2) and is reactive to rainfall events. The Roscommon rainfall also produced the highest average annual sediment output as a result of this storm, despite having the lowest average annual rainfall (Table 2). In comparison, both Cassilis and Scone rainfall produced very similar average annual sediment outputs. Nevertheless, both Cassilis and Scone had a large amount of variability in sediment output.
Table 2. Maximum annual sediment volume, average annual erosion for the simulation.

\begin{tabular}{lccc}
\hline & Roscommon & Cassilis & Scon। \\
Max. volume $\left(\mathrm{m}^{3}\right)$ & 118 & 50 & 45 \\
Average volume $\left(\mathrm{m}^{3} \mathrm{yr}^{-1}\right)$ & 11.0 & 8.5 & 7.9 \\
Std. Dev. volume $\left(\mathrm{m}^{3} \mathrm{yr}^{-1}\right)$ & 20.1 & 9.5 & 6.3 \\
Tonnes (ha $\left.\mathrm{yr}^{-1}\right)$ & 0.09 & 0.07 & 0.065 \\
\hline
\end{tabular}


Average erosion rates for the catchment were $0.09,0.07$ and $0.065 \mathrm{t} \mathrm{ha}^{-1} \mathrm{yr}^{-1}$ with peaks up to 118,50 and 45 $\mathrm{m}^{3}$ exiting the catchment per year for the three rainfall scenarios (Table 2). This high erosion rate for the Roscommon data are potentially realistic as the June 2007 storm was observed to produce severe erosion in the study catchment and surrounding region. To validate these erosion rate predictions they were compared to decadal scale soil erosion rates in the catchment quantified using the fallout radionuclide (Caesium-137) for the study catchment (Martinez et al., 2009). Catchment scale soil redistribution rates of $0.09-0.12 \mathrm{t} \mathrm{ha}^{-1}$ were calculated and is comparable to the rates predicted by CAESAR for the Roscommon $(0.09 \mathrm{t} / \mathrm{ha} / \mathrm{yr})$, Cassilis $(0.07 \mathrm{t} / \mathrm{ha} / \mathrm{yr})$ and Scone $(0.065 \mathrm{t} / \mathrm{ha} / \mathrm{yr})$ rainfall providing confidence in the model.

The different rainfall scenarios all produced changes in location and depth of the main channel and demonstrate individual channel responses to different rainfall patterns, with no surprising differences in hillslope form (Figure 3). Differences are most evident in the lower reaches of the catchment. Instead of following the existing channel, the simulation, using Roscommon rainfall, initiates a new channel that flows in a straight line at approximately 45 degrees to the existing channel and rejoins the existing channel near the catchment outlet and remains for the duration of the simulation. In the Cassilis rainfall simulations a new channel leaves the existing channel higher up the catchment than the Roscommon rainfall simulations, and follows a meandering course and remains for the duration of the simulation. This channel movement occurs within the first five years and, once fixed, these channels remain in their location for the duration of the simulation. Initial start conditions may play a role. The Scone rainfall produced no channel movement.

\section{DISCUSSION}

The rainfall data used here is from three different rainfall stations, while not covering the same period, each data set provides the longest set of rainfall data currently available from the nearest stations. The results demonstrate that different rainfall patterns produce distinct erosion rates as well as a change in channel location. A rainfall pattern (i.e. Roscommon) that has large and infrequent storms, yet has below average rainfall produces the highest average annual erosion rate. Low rainfall coupled with high intensity infrequent storms produces the highest erosion. Overall, relatively small changes in rainfall demonstrate a geomorphic sensitivity to subtle changes in climate.

Overall, the catchment has a low soil erosion rate but large storms can produce considerable erosion. This is to be expected as rainfall is relatively low, there is a consistent and well managed vegetation cover and the area is grazed very conservatively. The Stanley catchment has been monitored by the lead author since 2003 and the storm in June 2007 has been the only event to produce observable erosion in the catchment. The Cassilis and Scone rainfall, while on average higher, produce a lower annual erosion rate. Unfortunately neither data set contains the 2007 storm. This finding is supported by the property owners who have only seen erosion during storm events. At average annual time scales, erosion as quantified by the ${ }^{137} \mathrm{Cs}$ data is low and all the simulations produce erosion rates within the range of measured values for the catchment. The qualitative erosion rates and qualitative findings provide confidence in the model and its parameterisation at the decadal to centennial time scales examined here.

Previous work has demonstrated that autogenic processes in alluvial systems may lead to complex responses not only over geological time but much shorter time scales as well (Nicholas and Quinne, 2007). Mechanistically the change in channel location produced by the CAESAR model occurs as a result of sediment deposition at a constriction in the main channel. This constriction influences the flow and forces both water and sediment to overtop the channel and find an alternative path. This avulsion cuts a new channel or potentially in this case reactivates a former channel. Each simulation has an individual pattern as while the initial soil particle size distribution and DEM are identical the different rainfall patterns produce individual runoff and sediment transport regimes. The model results demonstrate the potential for internal fluvial feedbacks to drive dramatic and persistent channel movement and entrenchment in response to rainfall.

These results indicate that even within a relatively small and simple catchment there is a sensitivity to small changes in rainfall that lead to a bifurcation of change in system state (in this case avulsion to another channel path). Possibly this is a greater indicator of the non-linear nature of fluvial dynamics, and how rivers are sensitive to their initial conditions. Thus rather than being changed by significant forcings, they are vulnerable to small changes. Previous workers (Van de Wiel et al, 2007) have suggested that river catchments are non-linear systems and that when examining the sediment yields from catchments there can be considerable variability between identical sized events. These simulations illustrate how the channel position reflects a similar sensitivity. Therefore, the lateral movement is entirely driven by vertical erosion and deposition processes that are forcing the channel to find an alternate path. 


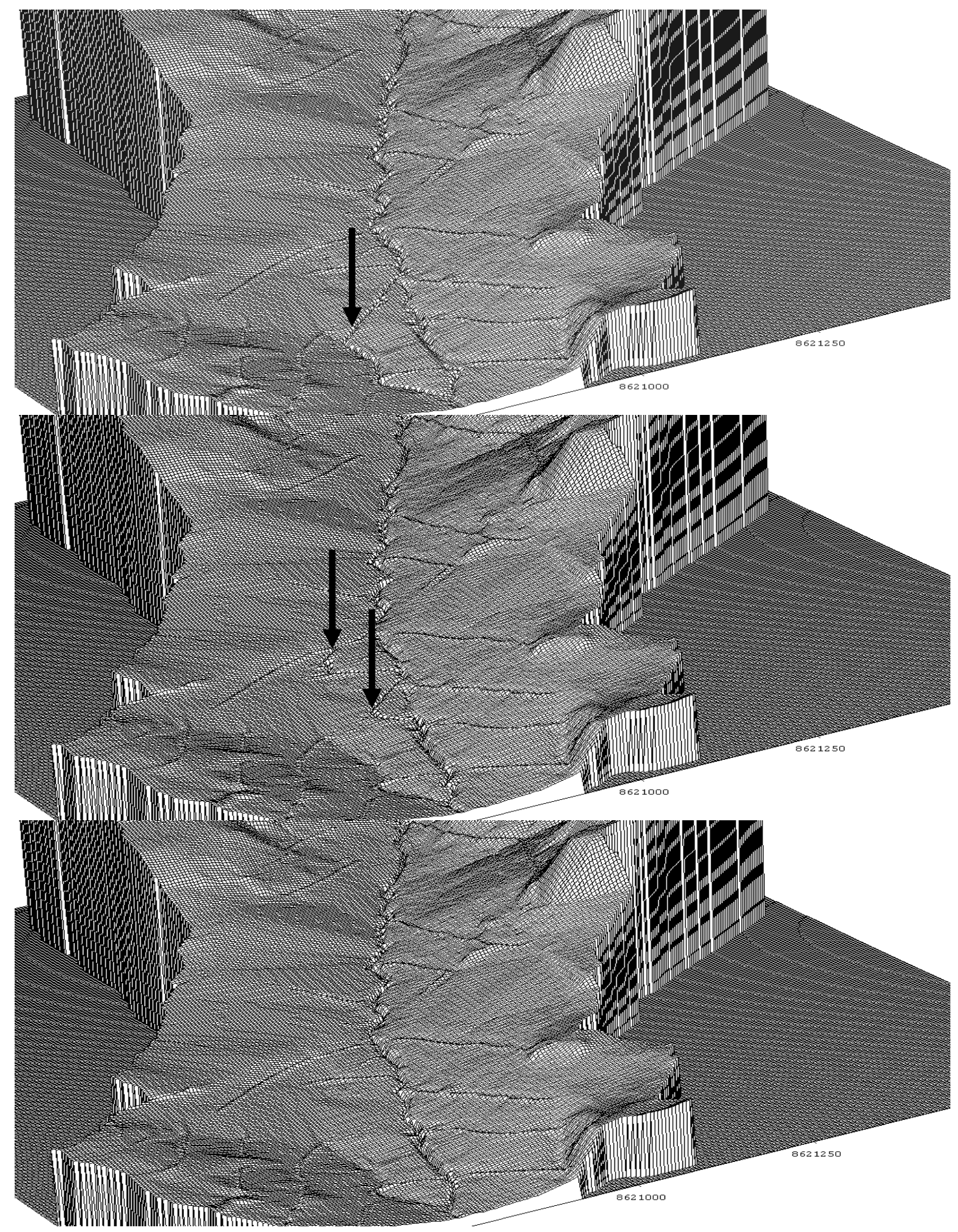

Figure 3. DEMs of the Stanley catchment using Roscommon (top), Cassilis (middle) and Scone (bottom) rainfall demonstrating the variation in channel location. The top section of the data has been removed for clarity. All dimensions are metres. 
In terms of changing rainfall patterns the results show that this catchment is geomorphologically sensitive. Temporally changing rainfall patterns, are shown here to have an effect on both erosion rates and channel location and movement. Reduced rainfall, coupled with increased storm intensity produces higher erosion rates and is likely to produce increased sediment loads to receiving waters therefore altering regional scale hydrology and sediment dynamics. This is currently being examined. This catchment is similar to many others in the area with vegetation, soil and management typical of the region and therefore the findings here are likely to be applicable in surrounding catchments.

\section{CONCLUSION}

Intrinsic and extrinsic forcing together with autogenic processes are known to lead to complex responses in the fluvial system. The model results here demonstrate that feedbacks as a result of sediment transport and associated aggradation and degradation drive the movement and entrenchment of channels in a relatively low rainfall environment. The findings have important implications for the role of autogenic feedbacks in fluvial systems that ultimately control landscape evolution. Neglecting these feedbacks and associated variability may result in simplified model outputs and an underestimate of environmental change.

Overall the CAESAR model appears to be able to replicate both erosion rates and the variation in channel movement that has occurred in the past. Channel movement occurs as an avulsion, this being the first time such a process has been modelled in a low rainfall environment. Therefore the model provides the ability to assess fluvial geomorphic change at decadal time scales. Rainfall in the study region has been shown to vary on multi-decadal time scales. Rainfall variability in response to climate change is a definite possibility in many regions. In areas like the Hunter Valley, increased storm frequency and intensity is likely to be coupled with extended periods of lower than the present average rainfall. The effects of potential changes need to be addressed so that climate change adaptation can take place. This is of considerable interest at present as the need to assess the impact of real or perceived climate change is vital for correct environmental decisions to be made.

\section{ACKNOWLEDGMENTS}

This research was supported by Australian Research Council Discovery Grant (DP 0556941: "Carbon, nutrient and sediment dynamics in a semi-arid catchment") and a Faculty of Science and Information Technology Strategic Research Initiative Fund (SIRF) (2011). Chris Dever provided considerable support in the measurement of soil depths and particle size distribution. Richard Dear provided computing support. This research was largely completed while on Special Studies Program leave at Oregon State University.

\section{REFERENCES}

Coulthard, T. (2001). Landscape evolution models: a software review, Hydrological Processes, 15:165-173.

Erskine, W., Warner, R. (1988). Geomorphic effects of alternating flood- and drought-dominated regimes on the N.S.W. coastal rivers, in Warner, R. F. (Ed.), Fluvial Geomorphology in Australia, Academic Press, Sydney, 223-244.

Knighton, D. (1998). Fluvial Forms and Processes: A New Perspective, Arnold, London.

Martinez, C., Hancock, G., Kalma J. (2009). Comparison of fallout radionuclide (caesium-137) and modelling approaches for the assessment of soil erosion rates for an uncultivated site in south-eastern Australia, Geoderma, 151, 128-140.

Nicholas, A., Quinne, T. (2007). Modelling alluvial landform change in the absence of external environmental forcing, Geology, 35, 6: 527-530.

Solyom, P., Tucker, G. (2004). Effect of limited storm duration on landscape evolution, drainage basin geometry, and hydrograph shapes, Journal of Geophysical Research, 109: 13.

Rüdiger, C., Hancock, G., Hemakumara, H. M., Jacobs, B., Kalma, J. D., Martinez, C., Thyer, M., Walker, J. P., Wells, T., Willgoose. G.R. 2007. Goulburn River experimental catchment data set, Water Resources Research, 43, W10403, doi:10.1029/2006WR005837

Tucker, G., Hancock, G. (2010). Modelling landscape evolution, Earth Surface Processes and Landforms, 35: 28-50.

Van De Wiel, M., Coulthard, T., Macklin, M. G., Lewin, J. (2007). Embedding reach-scale fluvial dynamics within the CAESAR cellular automaton landscape evolution model, Geomorphology, 90 (3-4), pp. 283301.

Verdon, D., Wyatt, A., Kiem, A., Franks, S. (2004). Multidecadal variability of rainfall and streamflow: Eastern Australia, Water Resources Research, 40, W10201, doi:10.1029/2004WR003234 